
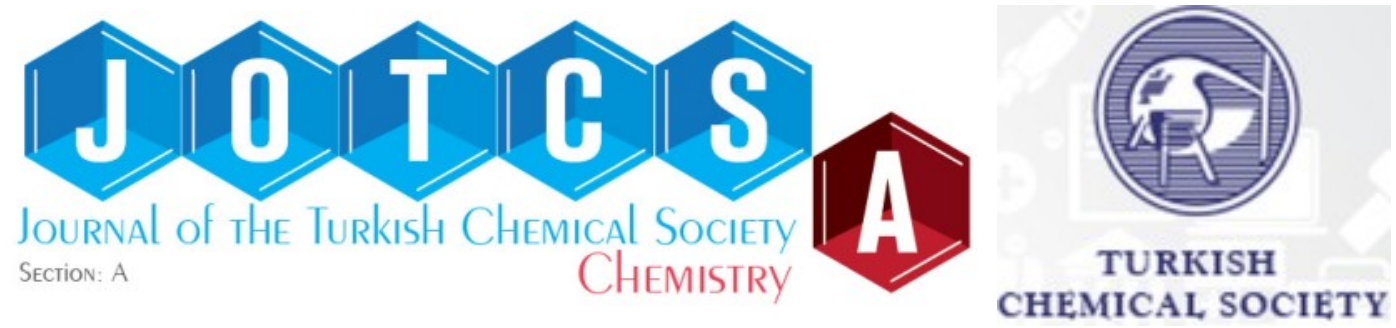

\title{
Surface Acidities of Bentonite, Sepiolite, and Synthetic Silica-Aluminas
}

\author{
Mehmet Kadir Yurdakoç $\triangle$ iD, Hasibe Bölük iD, Aylin Altınışık Tağaç \\ Dokuz Eylul University, Faculty of Science, Department of Chemistry, Izmir, Turkey
}

\begin{abstract}
The surface acidities of Bentonite, Sepiolite and Silica-Aluminas were determined by Hammett indicators, amine titrations, and of pyridine adsorption-IR spectroscopy. The quantitative estimation of surface acidities of silica-aluminas and their natures as Brønsted and Lewis acid sites were evaluated. Lewis and total surface acidity values of sepiolite were higher than bentonite, 0.53 and $2.22 \mathrm{mmole}^{-1}$, respectively. Surface acidity values of sepiolite and bentonite were much lower than Siral compounds. Among the Siral compounds, Siral 30 was found to be more effective in terms of acidity. All samples have both Lewis and Brønsted acid centers in which the Lewis sites predominated. IR spectroscopy with pyridine as a probe molecule was still very useful for the estimation of the surface acidities of the silica-alumina and also aluminosilicate structures such as clays and clay minerals.
\end{abstract}

Keywords: Surface acidity, Hammett indicators, amine titration, pyridine adsorption, FTIR spectroscopy

Submitted: April 02, 2021. Accepted: October 11, 2021.

Cite this: Yurdakoç MK, Bölük H, Altınışık Tağaç A. Surface Acidities of Bentonite, Sepiolite, and Synthetic Silica-Aluminas. JOTCSA. 2021;8(4):1153-64.

DOI: https://doi.org/10.18596/jotcsa.962665.

*Corresponding author. E-mail: k.yurdakoc@deu.edu.tr.

\section{INTRODUCTION}

Clays and clay minerals are used as catalytic carriers and direct catalysts because they contain silica and alumina. The catalytic properties of clays have also been the subject of many studies. Their catalytic activity results from the surface acidity, that is, from the Brønsted and Lewis acid centers they contain. Silica and alumina are also used as catalysts in chemical reactions (1-3). The surface acidities and catalytic activities of metal oxides, clay and clay minerals has been recently reported in a review article. (4).

In the determination of the surface acidity of the catalysts, Hammett indicators (5-8), amine titration (9), calorimetric method (10-12) and investigation of the gas phase adsorption of bases such as pyridine by FTIR method (13-18) were studied. Thermal desorption methods can also be used for the determination of the types of acid sites and their amounts in the catalysts $(5,12,19-22)$. Gas phase adsorption of pyridine onto metal oxides examined by IR spectroscopy used for the estimation of the surface acidities (23-27).
However, the results on the acidity of catalysts were not comparable as both the catalysts and acidity measurement methods in liquid phase or in gas phase. This is due to the fact that origins of the sites, the preparation methods and conditions (i.e. pretreatment, calcinations etc.) were arbitrarily different. The basic properties of silica and alumina and their mixtures, and especially the source of their acidic properties, were examined on a basic chemical content and published as a review article (28).

Clay minerals have Brønsted and Lewis acid sites because of their structures. The acidity and Brønsted to Lewis sites ratio related with the water content and $\mathrm{SiO}_{2} / \mathrm{Al}_{2} \mathrm{O}_{3}\left(\mathrm{Si}^{4+}, \mathrm{Al}^{3+}\right.$ and $\mathrm{Fe}^{3+}$ ions) of the mineral. The acidity of bentonite results from the removal of exchangeable cations from the structure and the removal of water. Anhydrous interlayer cations also function as Lewis acids (2933). Pyridine adsorption were also analyzed by density functional theory (DFT) simulations (34). 
In recent years, silica-alumina as catalyst carriers and their effects on catalytic activity in terms of acidities in various catalytic reactions has been investigated (35). Also, 2,4,6-tri-tert-butylpyridine (TTBP) was used as a new probe molecule for the determination of the acidities of zeolites as well as to silica and alumina (36). Nuclear magnetic resonance (NMR) relaxation time measurements and temperature-programmed desorption (TPD) techniques have also been developed as alternatives to IR spectroscopy, especially for zeolites (37).

The subject of this article, the surface acidity of synthetic Si-Al compounds, natural bentonite and sepiolite will be examined in terms of the amount of silica and their ratios they contain. The surface acid centers and amounts will also be studied. For this purpose, Hammett indicators, amine titration and FTIR spectroscopy investigation of in situ gas phase pyridine adsorption methods will be carried out.

\section{EXPERIMENTAL SECTION}

\section{Materials}

The chemical compositions of bentonite and sepiolite taken from Edirne and Eskişehir were given in a previous study (38). $\mathrm{SiO}_{2} / \mathrm{Al}_{2} \mathrm{O}_{3}$ ratios in bentonite and sepiolite samples were calculated as 3 and 96, respectively. The physicochemical properties of SIRAL samples are given in our previous study. SIRAL consists of synthetic silicon and aluminum oxide. It is given as an abbreviation for silica and alumina. $\mathrm{SiO}_{2} / \mathrm{Al}_{2} \mathrm{O}_{3}$ ratios in these compounds are given by the manufacturer as $20 \% \mathrm{SiO}_{2}$ and $80 \%$ $\mathrm{Al}_{2} \mathrm{O}_{3}$ in SIRAL 20 sample. Other chemicals used in our study were purchased from various companies as commercial and pure products and used as they are without any processing.

\section{Acid Strength Measurements}

Details about the experiment were given in a previous study (39). Therefore, it is briefly mentioned here. Dried powder samples were treated with three drops of all indicators in benzene. By looking at the color of the solution, it was decided whether the samples are basic to all indicators or the Ho, which was between the pKa of two consecutive indicators.

\section{Quantitative determination of acid sites}

In this method, the sample was first dispersed in benzene and then titrated with n-butyl amine in the presence of an indicator which was determined in acid strength measurement experiments. Dry benzene (sodium wire drawn) was chosen as a liquid that does not wet the surface and does not interact with the surface of the samples. If the liquid (or solvent) contains water or humidity from air, the acidity of the surface changes.

\section{Fourier Transform Infrared (FTIR)} Spectroscopic Analysis

At first, dry pure sample is tableted. The sample to be examined is taken into the IR cell and pretreated by heating at $110{ }^{\circ} \mathrm{C}$ under vacuum. The IR cell for gas phase used in the study is made of quartz, contains $\mathrm{NaCl}$ windows and has a heating system. Pyridine adsorption experiments were carried out in situ on pure tablets in the form of a gas phase in a special gas manipulation line setup. In our previous studies (39), a different FTIR device was used. IR spectra after each pyridine adsorption applied at certain time intervals and temperatures are recorded in Perkin-Elmer BX-II spectrometer. After the adsorption experiments, the desorption process is carried out by applying vacuum for 10 minutes at certain temperatures and recording the spectra at each stage. In the IR spectra recorded during the adsorption and desorption experiments, the area values below the relevant absorption bands are calculated. These area values were used in surface acidity calculations.

\section{RESULTS AND DISCUSSION}

\section{Acid Strength Measurements}

In the study conducted with Hammett indicators, it was determined that the samples were sensitive to which indicators in terms of surface acidity. Acidity strength measurement experiments were carried out on seven samples and eight indicators. The indicators used in the study and their $\mathrm{pK}_{\mathrm{a}}$ values were neutral red, $\mathrm{pK}_{\mathrm{a}}=+6.8$; methyl red, $\mathrm{pK}_{\mathrm{a}}=$ +4.8 ; 4-nitroaniline, $\mathrm{pK}_{\mathrm{a}}=+1.1$; crystal violet, $\mathrm{pK}_{\mathrm{a}}=+0.8 ;$ 2-nitroaniline, $\mathrm{pK}_{\mathrm{a}}=-0.2 ;$ 4-chloro-2nitroaniline, $\mathrm{pK}_{\mathrm{a}}=-0.9 ; 2,4$-dinitroaniline, $\mathrm{pK}_{\mathrm{a}}=-$ 4.4; anthraquinone, $\mathrm{pK}_{\mathrm{a}}=-8.2$, respectively. All samples showed positive color change only with neutral red and methyl red indicators. The studied substances give color conversion with the indicators of $\mathrm{pKa}$ values greater than +1.1 . As the pKa values increase, the acidity strength decreases. After the indicators were determined, butyl amine titration was performed for the estimation of quantitatively the acid strength and sites. Titrations were carried out with neutral red and methyl red indicators in benzene.

\section{n-butyl Amine Titration Results}

The titration results were presented in Table 1 . The total acidity of Siral samples was about 0.8 mmole/g. It increased with $\mathrm{SiO}_{2}$ content. In the case of clays, Bentonite was more acidic than Sepiolite, as 1.76 and 1.14 mmole $\mathrm{g}^{-1}$. This result may be due to $\mathrm{SiO}_{2}$ content. 
Table 1: The acidities from the n-butyl amine titration (mmole $\mathrm{g}^{-1}$ )

\begin{tabular}{llllllll}
\hline Indicator & Siral 5 & Siral 20 & Siral 30 & Siral 40 & Siral 80 & Sepiolite & Bentonite \\
\hline $\begin{array}{l}\text { Neutral red } \\
\text { (pKa }=+6.8)\end{array}$ & 0.17 & 0.20 & 0.24 & 0.28 & 0.45 & 0.57 & 0.26 \\
$\begin{array}{l}\text { Methyl red } \\
(\mathrm{pKa}=+4.8)\end{array}$ & 0.30 & 0.40 & 0.47 & 0.55 & 0.36 & 0.57 & 1.50 \\
\begin{tabular}{l} 
Total \\
\hline
\end{tabular} & 0.47 & 0.60 & 0.71 & 0.83 & 0.81 & 1.14 & 1.76 \\
\hline
\end{tabular}

It was published that the binary oxides such as $\mathrm{SiO}_{2}-\mathrm{Al}_{2} \mathrm{O}_{3}$ were more strongly acidic than the oxides alone when heating under vacuum. It was found that the acidity strength increased proportionally with increasing $\mathrm{SiO}_{2}$ amounts (1). This may be due to the water content of these samples and also the method of preparation. In another study, it was determined that grinding and steam heating changed the acidity strength (18).

\section{Fourier Transform Infrared Spectroscopic Experiments in Acidity}

(FTIR)

Today, as a standard method in surface acidity, the concentrations of Brønsted and Lewis acid sites are

Table 2: The acid sites as mmole $\mathrm{g}^{-1}$ from the adsorption of pyridine.

\begin{tabular}{ccc}
\hline Sample & $\mathrm{q}_{\mathrm{H}^{\mathrm{L}}}$ & $\mathrm{q}_{\mathrm{H}}^{\mathrm{B}}+\mathrm{q}_{\mathrm{H}^{\mathrm{L}}}$ \\
\hline Siral 5 & 1.23 & 2.55 \\
Siral 20 & 1.32 & 4.08 \\
Siral 30 & 3.16 & 4.86 \\
Siral 40 & 2.88 & 4.90 \\
Siral 80 & 3.09 & 4.24 \\
Sepiolite & 0.53 & 2.22 \\
Bentonite & 0.20 & 0.58 \\
\hline
\end{tabular}

calculated according to equation 1 as moles per dry sample weight (40).

$$
q_{H}=\frac{A \pi R^{2}}{w \epsilon}
$$

Where $A$ is the absorbance of the band from FTIR spectrum, $R$ is disk formed sample radius as $\mathrm{cm}$, and $\mathrm{w}$ is the sample weight as $\mathrm{g}$ before the experiment. $\varepsilon$, for the Brønsted and Lewis acid sites, the absorption bands at $1490 \mathrm{~cm}^{-1}$ and $1450 \mathrm{~cm}^{-1}$; 1.67 and $2.22 \mathrm{~cm}^{2} \mu \mathrm{mol}^{-1}$ were taken as reference, respectively (23). The acid sites were calculated from the equation (1) and given in Table 2.

The IR spectra of pyridine adsorbed on the samples were presented in Figures 1-7. Figure 1-3 were organized in a Supplementary File as S1. On the other hand, Siral 40, Siral 80, Sepiolite and Bentonite were given in Figures $4-7$, respectively. The pyridine bands used in the evaluation of the data in the FTIR spectroscopic examination of pyridine adsorption from the gas phase on solid samples are given in Table $3(14,15)$. All spectra (Figures 1-7) were evaluated according to this chart.

Table 3: The pyridine bands used in the evaluation of the data.

\begin{tabular}{ccccc}
\hline Type & $\mathrm{PY} \mathrm{\textrm {cm } ^ { - 1 }}$ & $\mathrm{HPY} \mathrm{cm}^{-1}$ & $\mathrm{BPY} \mathrm{cm}$ & $\mathrm{LPY} \mathrm{cm}^{-1}$ \\
\hline Mode $8 \mathrm{a}$ & 1582 & 1614 & 1639 & 1617 \\
$8 \mathrm{~b}$ & - & 1593 & 1613 & - \\
$19 \mathrm{a}$ & 1483 & 1490 & 1489 & 1495 \\
$19 \mathrm{~b}$ & 1440 & 1438 & 1539 & 1451 \\
\hline
\end{tabular}

Therefore, the observed bands at 1634, 1576 and $1394 \mathrm{~cm}^{-1}$ were defined to pyridinium ion as Brønsted species. For Lewis species, the bands at 1621,1576 and $1456 \mathrm{~cm}^{-1}$ were attributed. The band at $1490 \mathrm{~cm}^{-1}$ was related with BPY and LPY as stated in Table 3. This band was observed as common in all spectra (Figure 1-7). The band at $1456 \mathrm{~cm}^{-1}$ is also located in all spectra and can be taken close to the band at $1451 \mathrm{~cm}-1$, which is the closest for LPY, and shows Lewis acid locations. Pyridine is physically adsorbed by surface hydroxyl groups in the studied oxide structures. Absorption bands in the wavenumber range of $1590-1620 \mathrm{~cm}^{-1}$ appear as an indicator of this interaction. While $1595 \mathrm{~cm}^{-1}$ of these bands which was due to HPY species as in Table 3 observed especially in Siral compounds, it was not observed in sepiolite and bentonite. On the other hand, characteristic PY mode $8 a$ was observed at $1588 \mathrm{~cm}^{-1}$ in bentonite and sepiolite samples as in Figures 6 and 7 , respectively. Especially in the desorption experiments carried out at increasing temperatures, it was seen that a water molecule consisting of two hydroxyl groups leaving from the structures is strongly adsorbed on the surfaces, and it did not completely move away from the surface even in desorption at $573 \mathrm{~K}$.

In the mutual evaluation of the spectra (Figures 17), synthetic silica-alumina compounds (Sirals) and natural clays (bentonite, sepiolite) were selected according to their $\mathrm{SiO}_{2}$ and $\mathrm{Al}_{2} \mathrm{O}_{3}$ contents. In this respect, the spectra of Siral 40, Siral 80, sepiolite and bentonite (Figures 4-7) were clearly evaluated because of the $\mathrm{SiO}_{2}$ content.

Bands were observed at 1593, 1490 and $1456 \mathrm{~cm}^{-1}$ for Siral 40 in Figure 4. The band at $1490 \mathrm{~cm}^{-1}$ can be explained as pyridinium ion and pyridine bound to Lewis site. This band did not disappear in the 1155 
desorption experiment (Spectrum $f$ in Figure 4) conducted at $373 \mathrm{~K}$, and the desorptions carried out up to $573 \mathrm{~K}$ were also permanent. This was observed as an increase in band intensity in Siral 80 (Figure $5 a-f$ ). On the other hand, this band was relatively absent in sepiolite (Figure 6 ). In bentonite (Figure 7), band intensity was initially observed as very weak (spectrum b), then the band intensity increases and eventually becomes permanent. This was observed as an increase in band intensity in Siral 80 (Figure $5 a-f$ ). The band at $1490 \mathrm{~cm}^{-1}$ was relatively absent in sepiolite (Figure 6). In bentonite (Figure 7), band intensity was initially observed as very weak (spectrum b), increased gradually and the eventually becomes permanent. This behavior of the band at $1490 \mathrm{~cm}^{-1}$ can be interpreted as that pyridine interacts strongly with the Brønsted and Lewis acid centers on the surface and is also chemically adsorbed.

The bands observed at 1490 and $1456 \mathrm{~cm}^{-1}$ in Siral 40 (Fig. 4) were preserved, although the intensities decreased partially in desorption carried out with increasing temperature (Figure 4f). In Siral 80 (Figure 5), HPY (Mode 8b, Table 3) at $1595 \mathrm{~cm}^{-1}$ and 1454-1444 $\mathrm{cm}^{-1}$ (LPY) were observed. The bands at 1435, 1456, 1574 and $1588 \mathrm{~cm}^{-1}$ were observed for sepiolite (Figure 6).

There was an interesting situation here. All bands disappeared at $298 \mathrm{~K}$ during the desorption process. It can be interpreted that pyridine was poorly and physically adsorbed to the acid centers on the surface. If we look at the situation with bentonite, the band at $1490 \mathrm{~cm}^{-1}$ was gradually narrowed and its intensity decreased after desorption at $298 \mathrm{~K}$, but still observed the last desorption at $573 \mathrm{~K}$ (Figure $7 \mathrm{e}$ is not given here). Although common bands are observed at 1588, 1490 and $1456 \mathrm{~cm}^{-1}$ in the adsorption spectra of pyridine on sepiolite and bentonite, differences are observed especially in desorption spectra.

\section{CONCLUSION}

Surface acidity of silica-alumina compounds and the amount of acid centers vary depending on many factors such as $\mathrm{SiO}_{2} / \mathrm{Al}_{2} \mathrm{O}_{3}$ ratio, $\mathrm{SiO}_{2}$ percentage, preparation conditions, water content heat treatment. In situ adsorption/desorption experiments carried out in the gas phase where pyridine is used as the base and the monitoring of the processes with the IR method are quite fruitful. The method can be used as a standard in a wide range. While the order of total acidity values calculated according to the amine titration method in the samples was determined as Bentonite> Sepiolite $>$ Siral 40> Siral $80>$ Siral 30> Siral 20> Siral 5, the order according to FTIR data was quite different from the amine titration method as Siral 40> Siral 30> Siral 80> Siral 20> Siral 5> Sepiolite> Bentonite. All of the samples showed surface acidity and can be used as solid acid catalysts in a variety of reactions. 


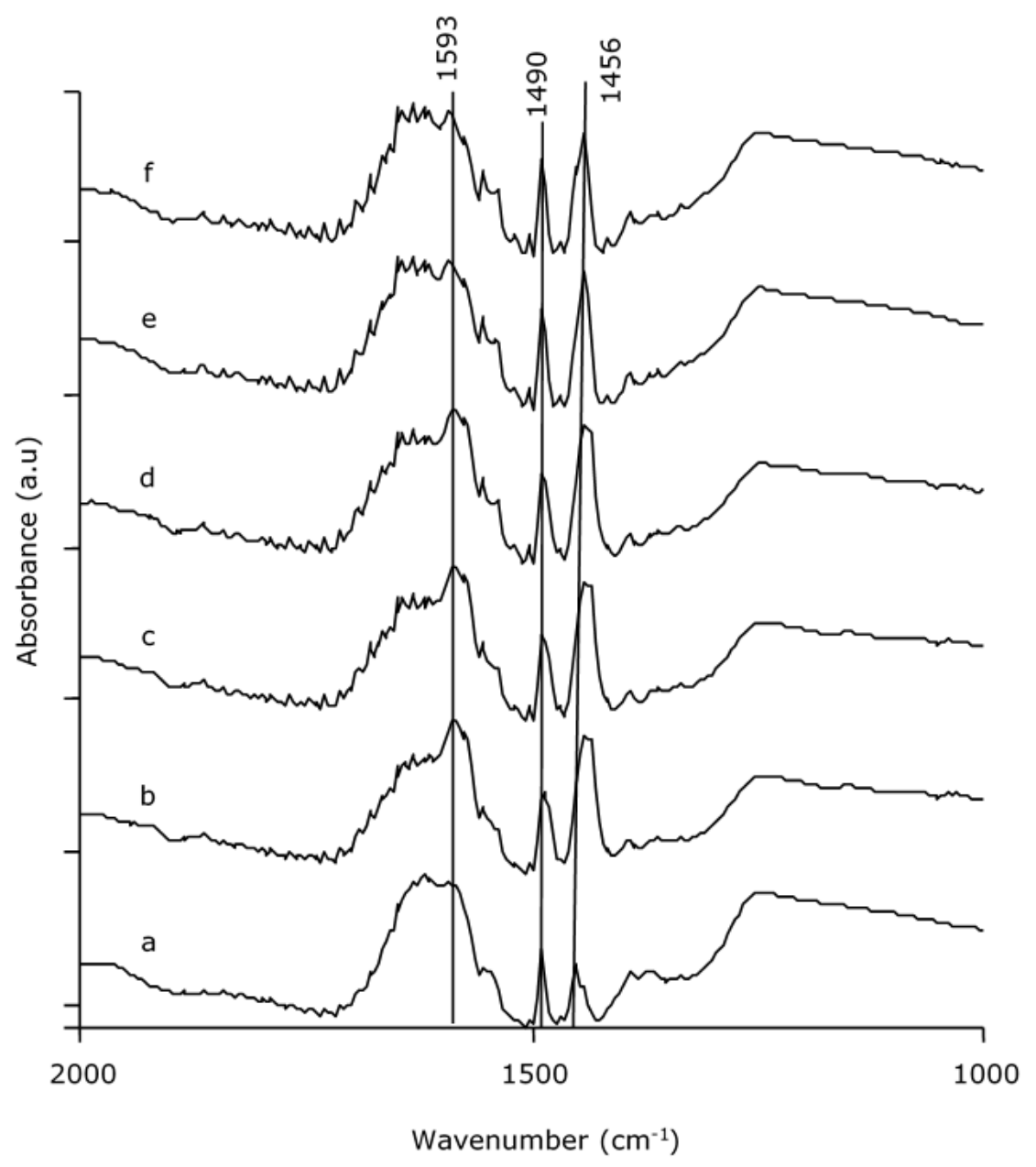

Figure 4: FTIR spectra of pyridine adsorbed on Siral 40 a) reference b) initial ads. c) $15 \mathrm{~min}$. ads d) $373 \mathrm{~K}, 30 \mathrm{~min}$. ads. e) $298 \mathrm{~K}, 5 \mathrm{~min}$. des. f) 373 K, $10 \mathrm{~min}$. des. 


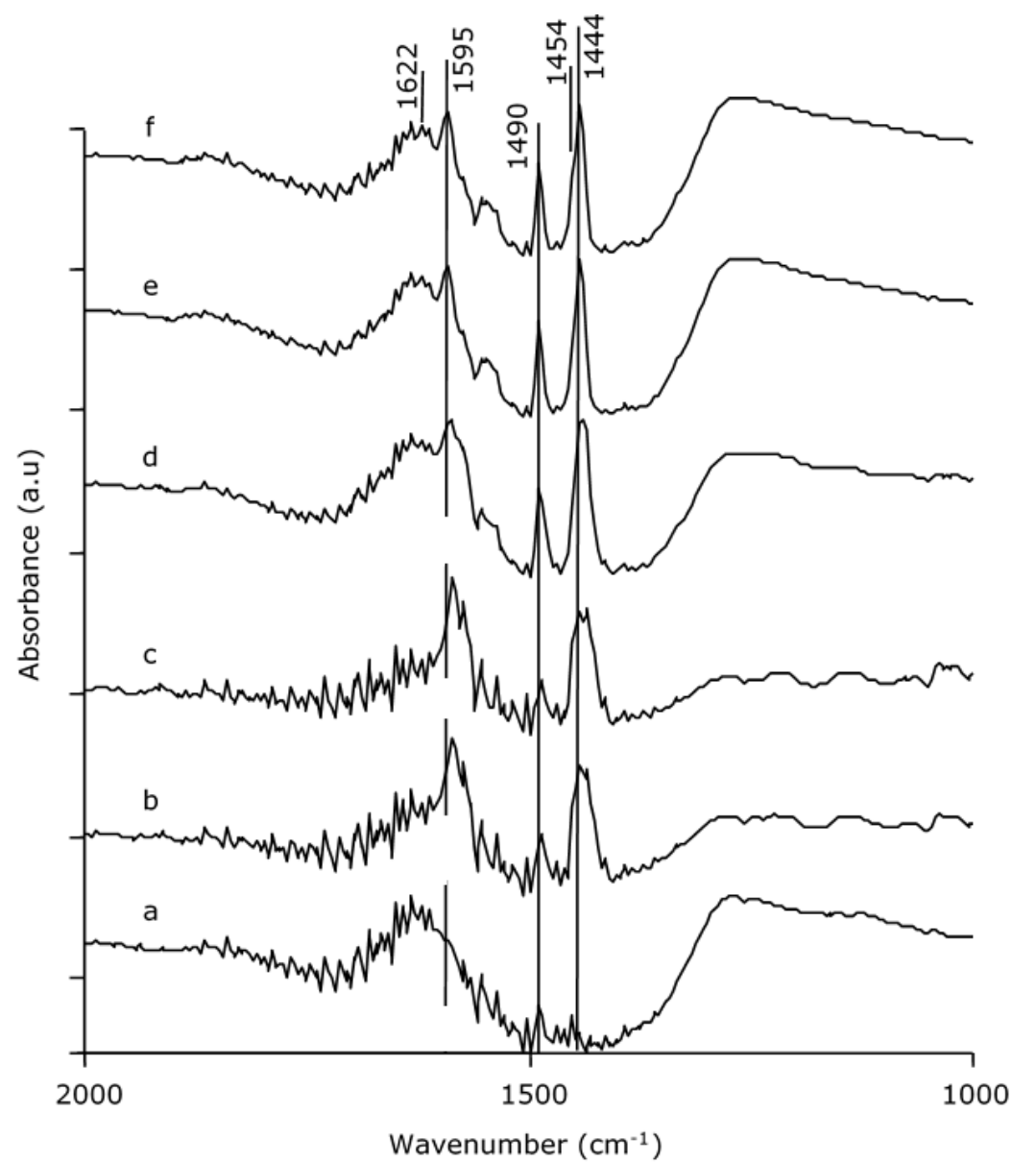

Figure 5: FTIR spectra of pyridine adsorbed/desorbed on Siral 80 a) reference b) initial ads. c) 15 min. ads. d) $373 \mathrm{~K}, 30 \mathrm{~min}$. ads. e) $298 \mathrm{~K}, 5 \mathrm{~min}$. des. f) $373 \mathrm{~K}, 10 \mathrm{~min}$. des.

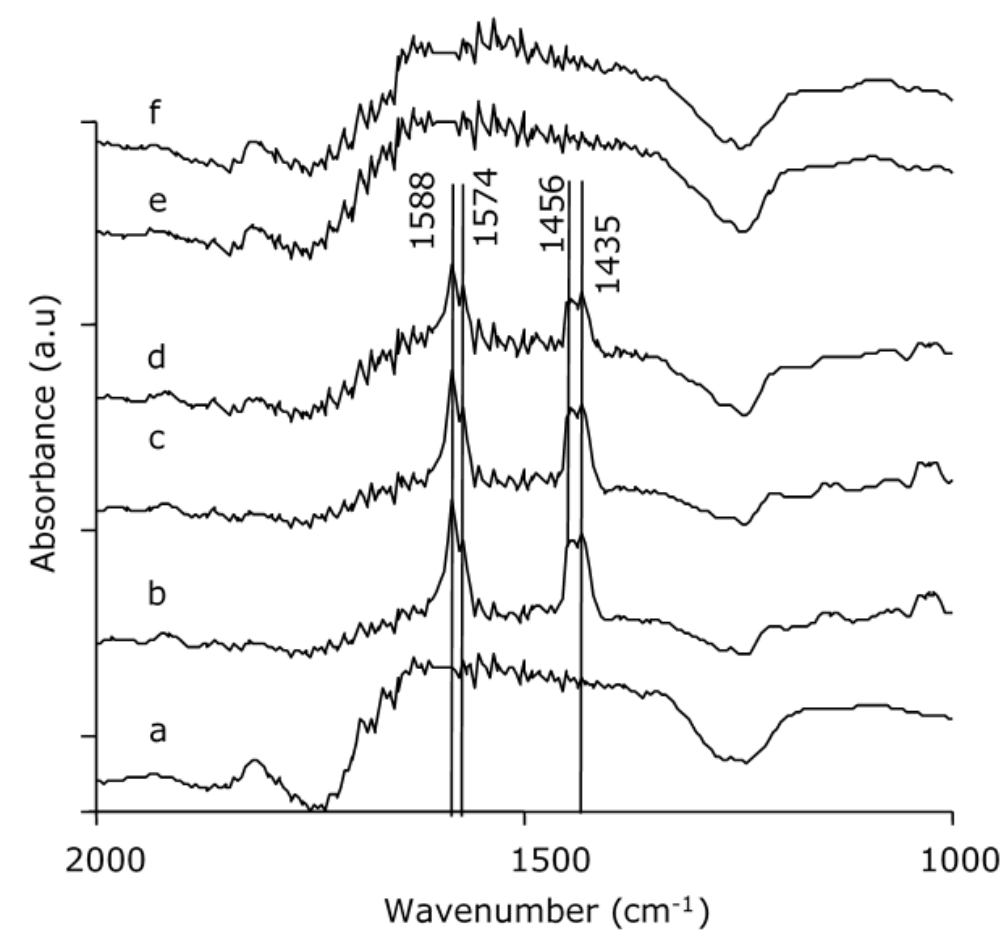

Figure 6: FTIR spectra of pyridine adsorbed / desorbed on Sepiolite a) reference b) initial ads. c) 15 min. ads. d) $373 \mathrm{~K}, 30 \mathrm{~min}$. ads. e) $298 \mathrm{~K}, 5 \mathrm{~min}$. des. f) $373 \mathrm{~K}, 10 \mathrm{~min}$. des. 


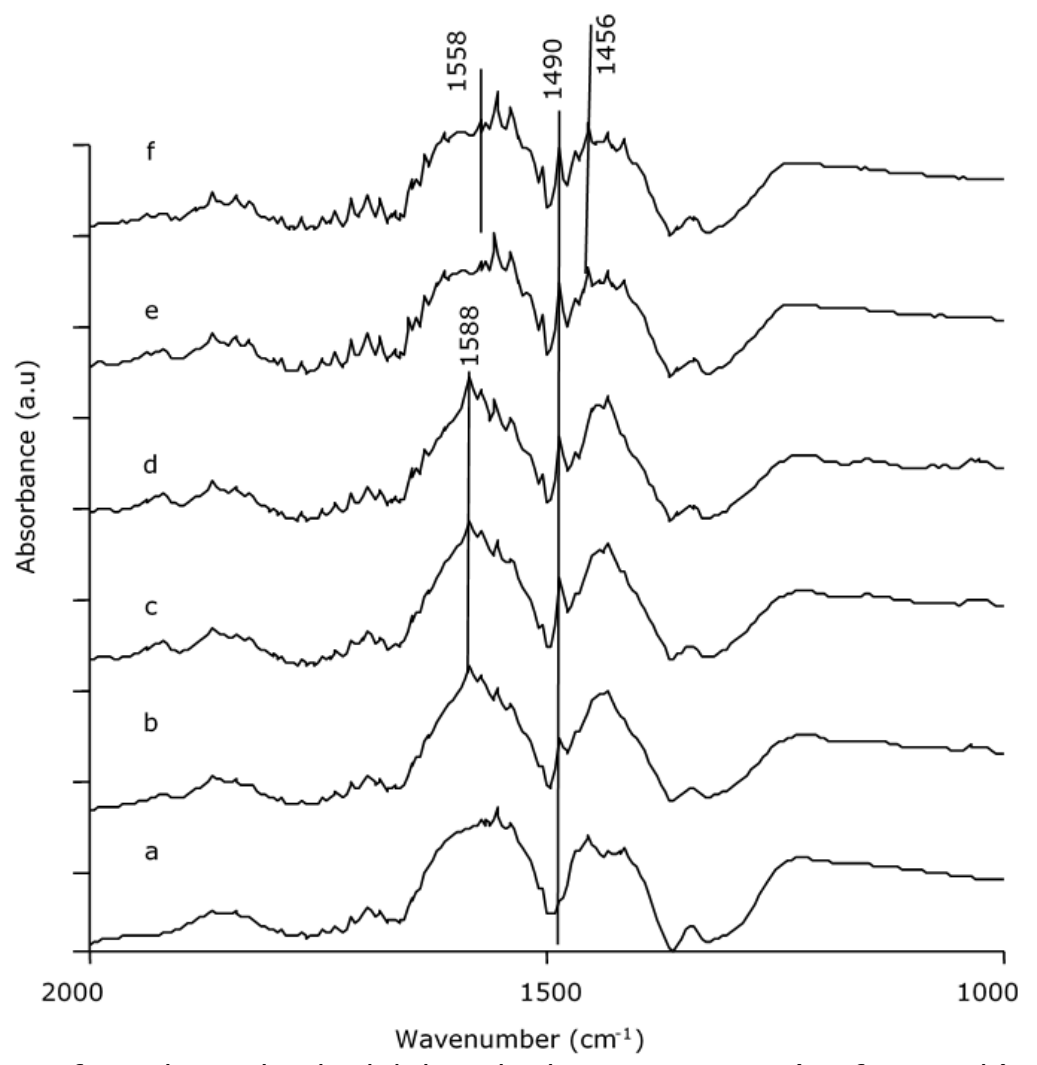

Figure 7: FTIR spectra of pyridine adsorbed / desorbed on Bentonite a) reference b) initial ads. c) 15 min. ads. d) $373 \mathrm{~K}, 30 \mathrm{~min}$. ads. e) $298 \mathrm{~K}, 5 \mathrm{~min}$. des. f) $373 \mathrm{~K}, 10 \mathrm{~min}$. des.

\section{CONFLICT OF INTEREST}

There is no conflict of interest with any institution or person.

\section{SUPPLEMENTARY INFORMATION}

FTIR spectrum results related to the adsorption of pyridine from the gas phase on Silica-alumina compounds (Siral 5, 20 and 30) are presented as supplementary file (S1) so that it does not take up too much space.

\section{REFERENCES}

1. Tanabe $\mathrm{K}$, Misono $\mathrm{M}$, Ono $\mathrm{Y}$, Hattori $\mathrm{H} .2$ Determination of Acidic and Basic Properties on Solid Surfaces. In: Studies in Surface Science and Catalysis [Internet]. Elsevier; 1989 [cited 2021 Oct 16]. p. 5-25. $\leq \mathrm{URL}>$

2. Kijeński J, Baiker A. Acidic sites on catalyst surfaces and their determination. Catalysis Today. 1989 Mar;5(1):1-120. <DOI .

3. Selli E, Forni L. Comparison between the surface acidity of solid catalysts determined by TPD and FTIR analysis of pre-adsorbed pyridine. Microporous and Mesoporous Materials. 1999 Oct;31(1-2):12940. $\leq \mathrm{DOI}>$.
4. Busca G, Gervasini A. Solid acids, surface acidity and heterogeneous acid catalysis. In: Advances in Catalysis [Internet]. Elsevier; 2020 [cited 2021 Oct 16]. p. $1-90$. $\leq U R L>$.

5. Liu D, Yuan P, Liu H, Cai J, Qin Z, Tan D, et al. Influence of heating on the solid acidity of montmorillonite: A combined study by DRIFT and Hammett indicators. Applied Clay Science. 2011 Jun;52(4):358-63. <DOI>.

6. Topaloğlu Yazıcı D, Bilgiç C. Determining the surface acidic properties of solid catalysts by amine titration using Hammett indicators and FTIRpyridine adsorption methods: Determining the surface acidic properties of solid catalysts. Surf Interface Anal. 2010 Jun;42(6-7):959-62. <DOI>.

7. Benesi HA. Acidity of Catalyst Surfaces. II. Amine Titration Using Hammett Indicators. J Phys Chem. 1957 Jul;61(7):970-3. <DOI>.

8. Hart MP, Brown DR. Surface acidities and catalytic activities of acid-activated clays. Journal of Molecular Catalysis A: Chemical. 2004 Apr;212(12):315-21. <DOI $>$.

9. Brown DR, Rhodes CN. Brønsted and Lewis acid catalysis with ion- exchanged clays. Catalysis Letters. $1997 ; 45(1 / 2): 35-40$. <DOI $>$. 
10. Breen C, Deane AT, Flynn JJ. The acidity of trivalent cation-exchanged montmorillonite. Temperature-Programmed desorption and infrared studies of pyridine and $\mathrm{n}$-butylamine. Clay miner. 1987 Jun;22(2):169-78. <DOI>.

11. Jankovic L. Metal cation-exchanged montmorillonite catalyzed protection of aromatic aldehydes with Ac20. Journal of Catalysis. 2003 Aug $15 ; 218(1): 227-33$. <DOI $>$.

12. Breen C. Thermogravimetric study of the desorption of cyclohexylamine and pyridine from an acid-treated Wyoming bentonite. Clay miner. 1991 Dec;26(4):473-86. <DOI >.

13. Richardson RL, Benson SW. A Study of the Surface Acidity of Cracking Catalyst. J Phys Chem. 1957 Apr;61(4):405-11. <DOI .

14. Basila MR, Kantner TR, Rhee KH. The Nature of the Acidic Sites on a Silica-Alumina. Characterization by Infrared Spectroscopic Studies of Trimethylamine and Pyridine Chemisorption 1. J Phys Chem. 1964 Nov;68(11):3197-207. <DOI>.

15. Bourne KH, Cannings FR, Pitkethly RC. Structure and properties of acid sites in a mixed-oxide system. I. Synthesis and infrared characterization. ] Phys Chem. 1970 May;74(10):2197-205. <DOI>.

16. Cannings FR. Acidic sites on mordenite: an infrared study of adsorbed pyridine. J Phys Chem. 1968 Dec;72(13):4691-3. <DOI>.

17. Parry E. An infrared study of pyridine adsorbed on acidic solids. Characterization of surface acidity. Journal of Catalysis. 1963 Oct;2(5):371-9. <DOI>.

18. Tanabe K. Solid acids and bases: their catalytic properties. Tokyo, New York: Kodansha; Academic Press; 1970. 175 p. ISBN: 978-0-12-683250-1.

19. Liu D, Yuan P, Liu H, Cai J, Tan D, He H, et al. Quantitative characterization of the solid acidity of montmorillonite using combined FTIR and TPD based on the NH3 adsorption system. Applied Clay Science. 2013 Aug;80-81:407-12. <DOI>.

20. Bilgiç C, Topaloglu Yazıcl D, Vural N. Characterizing the surface acidity of bentonite by various methods: The surface acidity of bentonite. Surf Interface Anal. 2010 Jun;42(6-7):1000-4. $<$ DOI $>$.

21. Benaliouche $F$, Boucheffa $Y$, Ayrault $P$, Mignard $S$, Magnoux P. NH3-TPD and FTIR spectroscopy of pyridine adsorption studies for characterization of $\mathrm{Ag}$ - and $\mathrm{Cu}$-exchanged $\mathrm{X}$ zeolites. Microporous and Mesoporous Materials. 2008 Apr;111(1-3):80-8. $\leq \mathrm{DOI}>$.
22. Hughes TR, White HM. A study of the surface structure of decationized $Y$ zeolite by quantitative infrared spectroscopy. J Phys Chem. 1967 Jun;71(7):2192-201. <DOI>.

23. Emeis CA. Determination of Integrated Molar Extinction Coefficients for Infrared Absorption Bands of Pyridine Adsorbed on Solid Acid Catalysts. Journal of Catalysis. 1993 Jun;141(2):347-54. <DOI>.

24. Makarova MA, Karim K, Dwyer J. Limitation in the application of pyridine for quantitative studies of brönsted acidity in relatively aluminous zeolites. Microporous Materials. 1995 Jun;4(2-3):243-6. $\leq \mathrm{DOI}$.

25. Khabtou S, Chevreau T, Lavalley JC. Quantitative infrared study of the distinct acidic hydroxyl groups contained in modified $Y$ zeolites. Microporous Materials. 1994 Sep;3(1-2):133-48. $\leq$ DOI $>$.

26. Datka J. Acidic properties of supported niobium oxide catalysts: An infrared spectroscopy investigation. Journal of Catalysis. 1992 May;135(1):186-99. <DOI>.

27. Turek AM, Wachs IE, DeCanio E. Acidic properties of alumina-supported metal oxide catalysts: an infrared spectroscopy study. J Phys Chem. 1992 Jun;96(12):5000-7. <DOI>.

28. Busca G. Catalytic materials based on silica and alumina: Structural features and generation of surface acidity. Progress in Materials Science. 2019 Jul;104:215-49. <DOI .

29. Akçay M. FT-IR spectroscopic investigation of the adsorption pyridine on the raw sepiolite and Fepillared sepiolite from anatolia. Journal of Molecular Structure. 2004 Jun;694(1-3):21-6. <DOI>.

30. Akçay $M$. The surface acidity and characterization of Fe-montmorillonite probed by in situ FT-IR spectroscopy of adsorbed pyridine. Applied Catalysis A: General. 2005 Oct;294(2):15660. $<$ DOI $>$.

31. Madejová J. FTIR techniques in clay mineral studies. Vibrational Spectroscopy. 2003 Jan;31(1):1-10. <DOI>.

32. Yariv S, Michaelian K. Structure and surface acidity of clay minerals. In: Yariv $S$, Cross $H$, editors. Organo-clay complexes and interactions. New York: Marcel Dekker; 2002. p. 1-38. ISBN: 978-0-8247-0586-2.

33. Heller-Kallai L. Clay catalysis in reactions of organic matter. In: Organo-Clay Complexes and Interactions. New York: Marcel Dekker; 2002. p. 567-614. ISBN: 978-0-8247-0586-2. 
34. Jystad A, Leblanc $H$, Caricato M. Surface Acidity Characterization of Metal-Doped Amorphous Silicates via Py-FTIR and 15 N NMR Simulations. J Phys Chem C. 2020 Jul 16;124(28):15231-40. $\leq \mathrm{DOI}>$

35. Saito $M$, Aihara $T$, Miura $H$, Shishido T. Brønsted acid property of alumina-based mixed-oxidessupported tungsten oxide. Catalysis Today. 2021 Sep;375:64-9. <DOI>.

36. Beutel TW, Willard AM, Lee C, Martinez MS, Dugan R. Probing External Brønsted Acid Sites in Large Pore Zeolites with Infrared Spectroscopy of Adsorbed 2,4,6-Tri-tert-butylpyridine. J Phys Chem C. 2021 Apr 29;125(16):8518-32. <DOI>.

37. Robinson N, Bräuer P, York APE, D'Agostino C. Nuclear spin relaxation as a probe of zeolite acidity: a combined NMR and TPD investigation of pyridine in HZSM-5. Phys Chem Chem Phys. 2021;23(33):17752-60. <DOI>.

38. Cengiz S, Çavaş L, Yurdakoç K. Bentonite and sepiolite as supporting media: Immobilization of catalase. Applied Clay Science. 2012 Sep;6566:114-20. <DOI>.

39. Yurdakoç $M$, Akçay $M$, Tonbul $Y$, Yurdakoç $K$. Acidity of silica-alumina catalysts by amine titration using Hammett indicators and FT-IR study of pyridine adsorption. Turk J Chem. 1999;23(3):319218. $\leq$ URL>.

40. Barzetti T, Selli E, Moscotti D, Forni L. Pyridine and ammonia as probes for FTIR analysis of solid acid catalysts. Faraday Trans. 1996;92(8):1401. <DOI $>$. 


\section{Surface Acidities of Bentonite, Sepiolite, and Synthetic Silica-Aluminas} Mehmet Kadir Yurdakoç $\triangle$ iD, Hasibe Bölük iD, Aylin Altınışık Tağaç Supplementary File (S1)

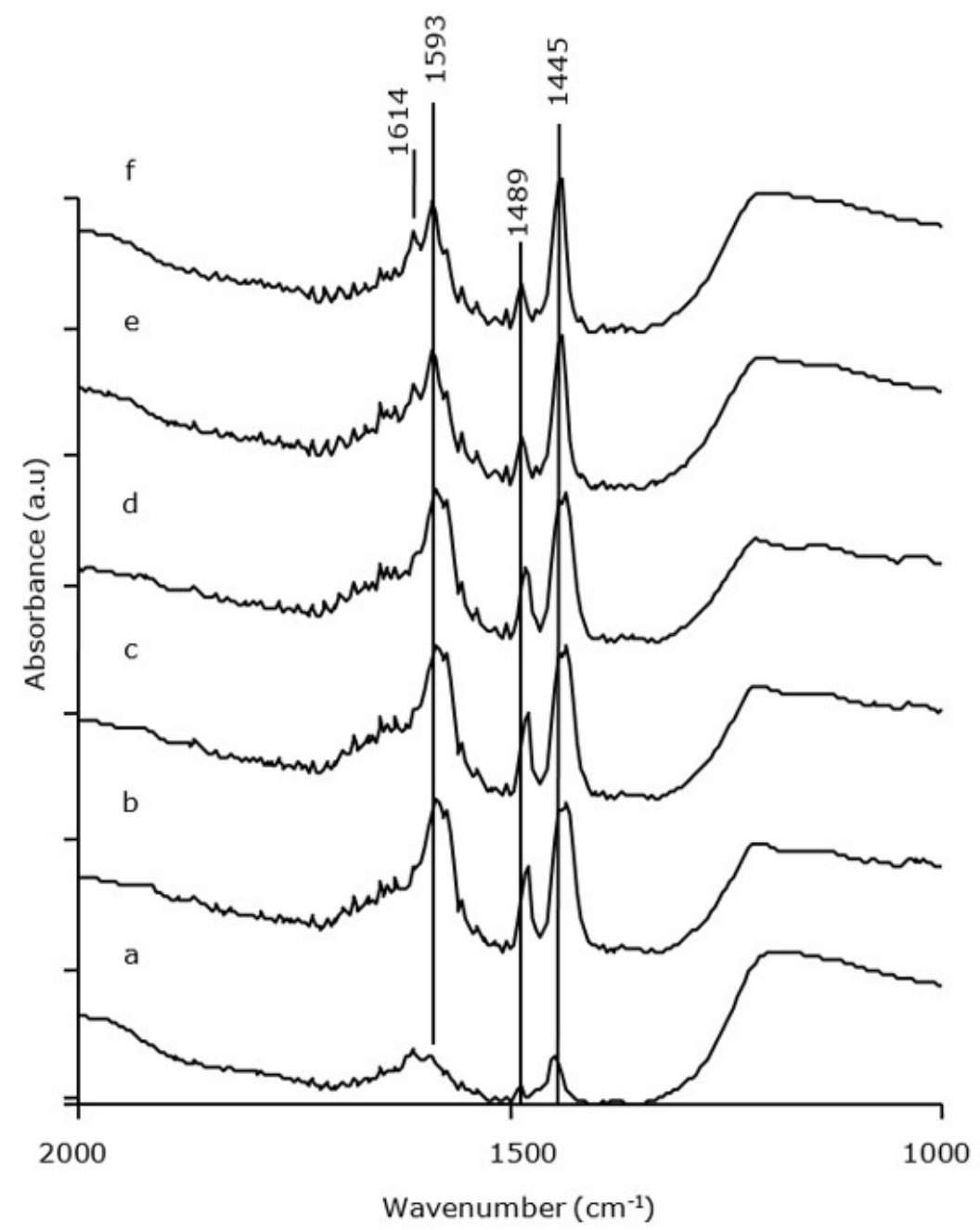

Figure S1: FTIR spectra of pyridine adsorbed/desorbed on Siral 5 a) reference b) initial ads. c) 15 min. ads. d) 373 K, 30 min. ads. e) 298 K, 5 min. des. f) 373 K, 10 min. des. 


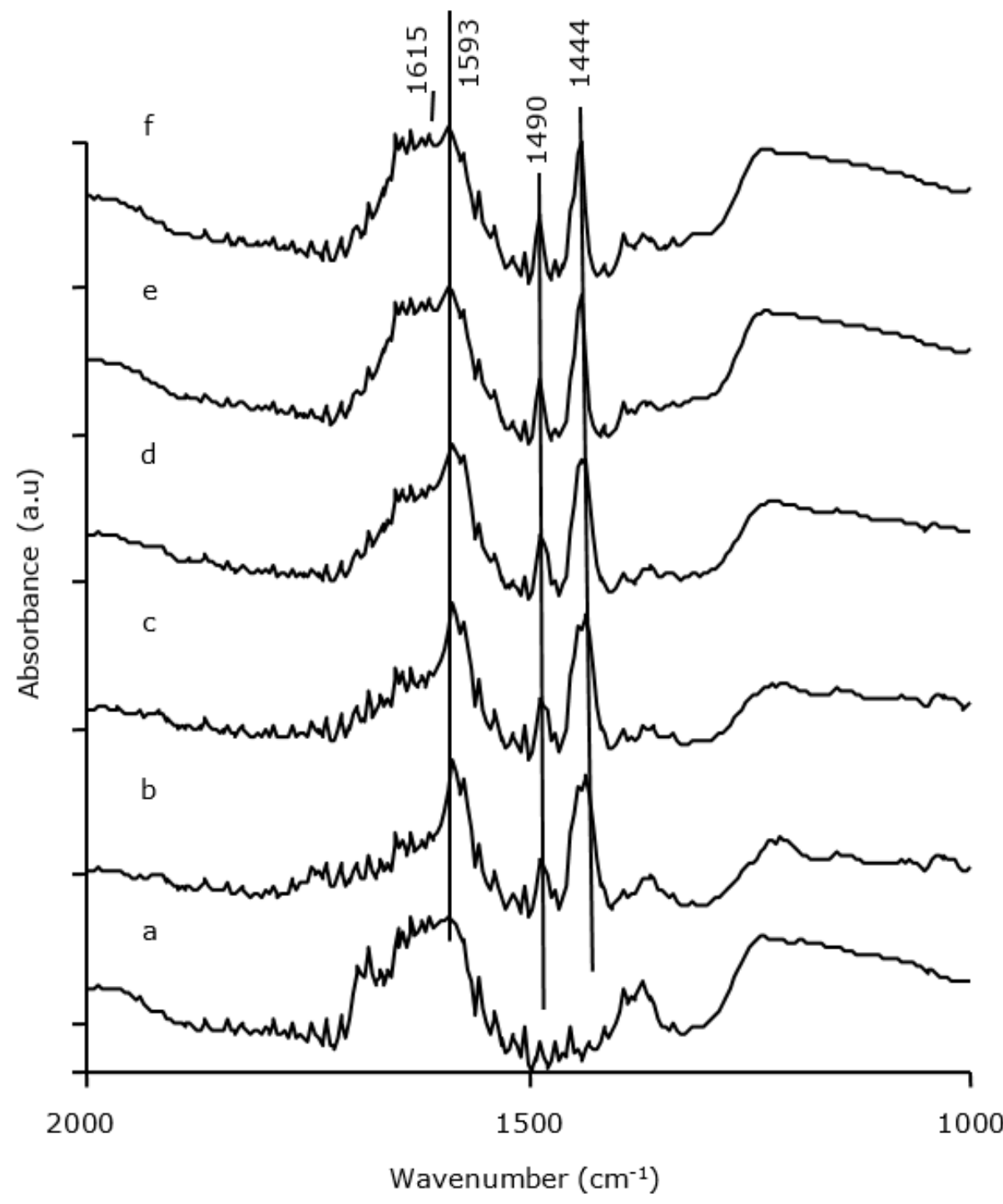

Figure S2: FTIR spectra of pyridine adsorbed/desorbed on Siral 20 a) reference b) initial ads. c) 15 min. ads. d) 373 K, 30 min. ads. e) 298 K, 5 min. des. f) 373 K, 10 min. des. 


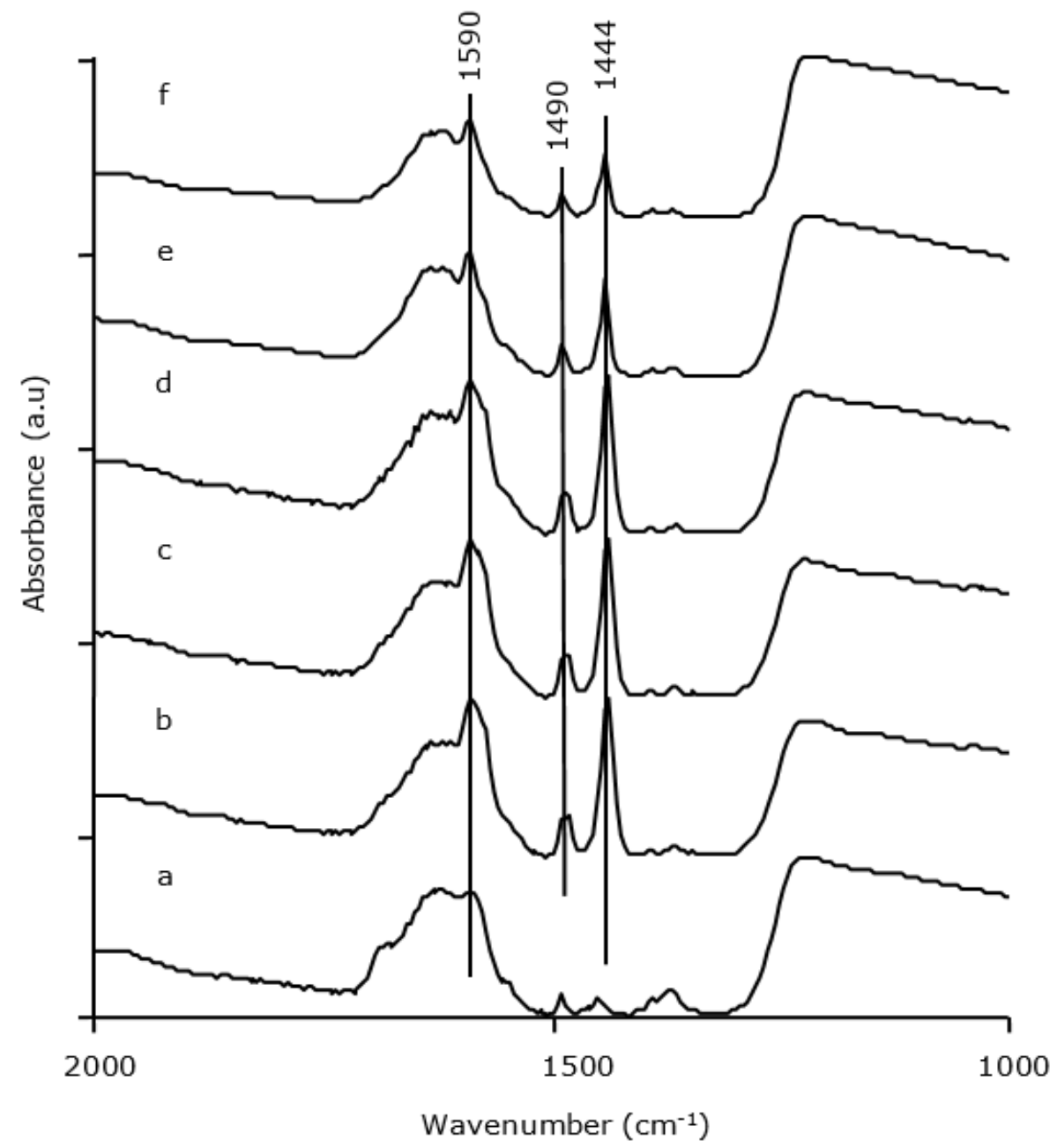

Figure S3: FTIR spectra of pyridine adsorbed/desorbed on Siral 30 a) reference b) initial ads. c) 15 min. ads. d) 373 K, 30 min. ads. e) 298 K, 5 min. des. f) 373 K, 10 min. des. 